\section{A WELCOME TO THE HORIZON 2020 PROGRAMME}

\section{What is Horizon 2020?}

Horizon 2020 is the financial instrument implementing the Innovation Union, a Europe 2020 flagship initiative aimed at securing Europe's global competitiveness [...] By coupling research and innovation, Horizon 2020 is helping to achieve this with its emphasis on excellent science, industrial leadership and tackling societal challenges. The goal is to ensure Europe produces world-class science, removes barriers to in novation and makes it easier for the public and private sectors to work together in delivering innovation. [1]

\section{Where is Transport in Horizon 2020?}

Horizon 2020, the successor to the Seventh Framework Programme, is divided into several sections and measures. The three main sections are Excellent Science, Industrial Leadership and Societal Challenges. The Societal Challenges section, among other, contains the Smart, Green and Integrated Transport challenge, a highly relevant topic within the scope of Promet-Traffic\&Transportation.

This Challenge aims to boost the competitiveness of the European transport industries and achieve a European transport system that is resource-efficient, climate-and- environmentally-friendly, safe and seamless for the benefit of all citizens, the economy and society. Horizon 2020 will provide funding for a resource efficient transport that respects the environment by making aircraft, vehicles and vessels cleaner and quieter to minimize transport systems' impact on climate and the environment, by developing smart equipment, infrastructures and services and by improving transport and mobility in urban areas. Horizon 2020 also aims at a better mobility, less congestion, more safety and security with a substantial reduction of traffic congestion; with a substantial improvement in the mobility of people and freight; by developing new concepts of freight transport and logistics and by reducing accident rates, fatalities and casualties and improving security. [2]

Other sections and challenges in the programme, such as the Excellent Science section, also contain topics relevant to the scope of PrometTraffic\&Transportation.

\section{How are the journal and its publisher participating in Horizon 2020?}

Promet-Traffic\&Transportation is published by the Faculty of Transport and Traffic Sciences, University of Zagreb, the leading high education as well as scientific and research institution in the field of transport and traffic engineering in Croatia. Among other international projects, the Faculty has participated in several research projects within the Seventh Framework Programme (CIVITAS ELAN [3], ICSI [4]) and is submitting several project proposals within the Horizon 2020 programme. The journal is supported by an international team of co-publishers from several European countries. The team consists of the Faculty of Maritime Studies and Transport from the University of Ljubljana, Faculty of Operation and Economics of Transport and Communications from the University of Žilina, Jan Perner Transport Faculty from the University of Pardubice, Faculty of Transport and Communication from the University of Sarajevo and the Institute for Transport Studies Within the European Economic Integration from Trieste.

The journal is indexed in SCIE, SCOPUS, TRID and other relevant bases and therefore we believe it can serve as an excellent platform for dissemination of research results and project information. The editorial team of the journal would like to invite all Horizon 2020 projects' participants to present their work in the periodical section of the journal. The project presentations should contain the project title, overall value, origin of funding (programme or action title), duration, list of partners and a short description with clearly stated project goals or results.

\section{What is the Open Access policy in Horizon 2020?}

Open access is a policy of providing free and unlimited access to scientific research and publications. Open access can further be divided into two major types, green and gold open access, or self-archiving and open access journals, respectively.

In December 2013 the European Commission published the Guidelines on Open Access to Scientific Publications and Research Data in Horizon 2020 [5]. The guidelines further explain the conditions of open access which can be mandated in projects funded under Horizon 2020. The mandate states that all publications, and in some cases, research data which is a result of a Horizon 2020 project should be published using open access practices. Both self-archiving (green open access) and open access publishing (gold open access) supported. It is also stated that publishing costs of Horizon 2020 project research incurred by authors are eligible for reimbursement.

The Journal Promet-Traffic\&Transportation fully supports the open access policy and welcomes all Horizon 2020 related article submissions.

Nikola Bakarić, M.A. International Cooperation Office Faculty of Transport and Traffic Sciences University of Zagreb 


\section{REFERENCES}

[1] What is Horizon 2020? [Internet]. [cited 2015 Feb 9]. Available from: http://ec.europa.eu/programmes/horizon2020/en/what-horizon-2020

[2] Smart, Green and Integrated Transport [Internet]. [cited 2015 Feb 9]. Available from: http://ec.europa.eu/ programmes/horizon2020/en/h2020-section/smartgreen-and-integrated-transport
[3] CIVITAS ELAN project "Mobilising citizens for vital cities" [Internet]. [cited 2015 Feb 9]. Available from: http://www.civitas-initiative.org/content/elan

[4] ICSI - Intelligent Cooperative Sensing for Improved Traffic Efficiency [Internet]. [cited 2015 Feb 9]. Available from: http://www.ict-icsi.eu/

[5] European Commission. Guidelines on Open Access to Scientific Publications and Research Data in Horizon 2020. 2013 p. 1-14. 